\title{
Perancangan Real Time Monitoring Temperatur Berbasis Mikrokontroler Untuk Sistem Trip Otomatis Motor Listrik 3 (Tiga) Fasa Fibre Cyclone di Pabrik Kelapa Sawit Sungai Bengkal Jambi
}

\author{
Hanifadinna ${ }^{1,1 *}$, Deni Rachmat ${ }^{1}$, Azka Gilang Borneo \\ ${ }^{1}$ Program Studi Teknologi Pengolahan Sawit, Fakultas Vokasi, Institut Teknologi Sains Bandung, Indonesia
}

\begin{abstract}
Abstrak.
Motor listrik merupakan salah satu instrumen yang memegang peranan penting dalam mengendalikan pergerakan mesin-mesin produksi di Pabrik Kelapa Sawit (PKS). Pada PKS Sungai Bengkal Jambi, proses penggantian atau rekondisi sebuah motor listrik dengan daya $60 \mathrm{HP}$ akibat overheat (terbakar) memerlukan waktu lebih dari 1 (satu) bulan. Untuk menanggulangi hal tersebut, dirancang suatu sistem kontrol tertutup yang terdiri dari sensor, indikator, kontroler, dan aktuator. Sistem dibuat dengan menggunakan sensor IC LM35 untuk mendeteksi temperatur bagian dalam motor listrik. Informasi temperatur dari sensor tersebut diterima dan diolah oleh mikrokontroler yang diprogram untuk merespon perubahan temperatur dan memberikan feedback dengan melakukan trip pada motor listrik saat temperatur operasi melebihi set point yang telah ditentukan. Setelah loop selesai, sistem akan mengaktifkan kembali motor listrik saat temperatur operasi sudah kembali normal. Feedback yang diberikan juga digunakan sebagai sistem peringatan dini (early warning system dengan menambahkan lampu indikator dan sirine pada sistem. Selain itu, mikrokontroler diprogram untuk mengkonversi perubahan temperatur dari sensor untuk diolah menjadi keluaran data digital. Semua data tersimpan dalam data logger (perekam data) dan ditampilkan secara langsung pada sevent segment display. Untuk menguji akurasi sistem, telah dilakukan pengambilan data temperatur sebanyak 30 kali melalui data logger. dan didapatkan nilai standar deviasi sebesar $0,77 \%$ dengan rentang sebesar $0,71^{\circ} \mathrm{C}$. Perbedaan hasil pengukuran jika dibandingkan dengan Termolaser adalah sebesar 0,013\%.
\end{abstract}

Kata kunci : Mikrokontroler, data logger, early warning, motor listrik 3 (tiga) fasa, realtime monitoring, sistem trip

\section{Pendahuluan}

Motor Listrik 3 (Tiga) Fasa merupakan mesin yang sangat krusial karena manfaat dan penggunaannya sangat luas pada Pabrik Kelapa Sawit (PKS). Hampir di setiap stasiun kerja menggunakan motor listrik sebagai penggerak utama mesin-mesin produksi. Berdasarkan histori, kerusakan motor listrik 3 (tiga) fasa akibat overheat di PKS Sungai Bengkal Jambi, terjadi paling sedikit 24 kali dalam kurun waktu 6 (enam) bulan pada tahun 2017. Untuk satu unit motor listrik 3 (tiga) fasa TECO berdaya $60 \mathrm{HP}$, (380 V, 90 A, kelas isolasi F, 1465), yang mengalami overheat (terbakar) membutuhkan waktu tidak kurang dari 1 (satu) bulan dalam proses rekondisi atau rewinding dengan biaya sekitar Rp. 8.000.000. Dampak kerusakan motor listrik akan menjadi sangat fatal jika terjadi pada motor listrik fibre cyclone.

\footnotetext{
1* Corresponding author: hanifadinna@gmail.com
}

Fibre Cyclone adalah salah satu unit mesin pada Kernel Plant (Nut and Kernel Station) yg berfungsi untuk memisahkan fibre dan nut yg berasal dari press cake (keluaran mesin screw press). Motor listrik pada Fibre Cyclone merupakan penggerak utama mesin produksi yang disebut Mesin Depericarper. Depericarper merupakan mesin terintegrasi dengan Fibre Cyclone dengan fungsi sebagai pemindah seratserat (fibres) yang bercampur dengan nut keluaran dari Mesin Cake Breaker Conveyor (CBC). Jika proses pemindahan tidak dapat dilakukan akibat motor listrik Fibre Cyclone tidak berfungsi, maka proses pemisahan antara serat dan nut tidak akan terjadi atau proses produksi pada Stasiun Nut dan Kernel dapat dinyatakan tidak beroperasi. Tidak beroperasinya Stasiun Nut dan Kernel 
Research Paper Vol 3, No 2, Tahun 2021

menyebabkan proses produksi PKS terhenti (trip).

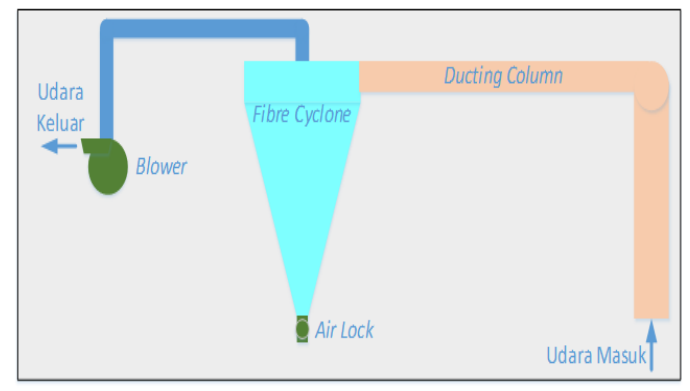

Gambar 1. Pneumatic Transport System Fibre Cyclone Menggunakan Motor Listrik 3 (Tiga) Fasa pada Bagian Blower

Jika mesin Fibre Cyclone ini tidak berfungsi maka Nut tidak dapat diolah menjadi Kernel dan Shell. Selain itu dampak lainnya supply bahan bakar (fibre) untuk Boiler menjadi terhenti.

Motor listrik fibre cyclone terletak di lantai atas Stasiun Nut dan Kernel pada ketinggian 15 meter dari lantai stasiun tersebut seperti terlihat pada Gambar 1. Selain terletak pada ketinggian, motor listrik juga berada pada lingkungan yang kurang baik, yaitu berada di luar naungan atap bangunan pabrik yang terkena sinar matahari langsung dan sulit dijangkau. Jenis tangga tegak berjumlah lebih dari 1 (satu) buah tangga tegak menyebabkan akses menuju motor listrik sulit dilakukan. Meskipun motor listrik ditutupi dengan bekas drum PVC yang dimodifikasi, akan tetapi belum dapat menggantikan kondisi yang baik di dalam naungan atap seperti ditunjukkan pada Gambar 2.

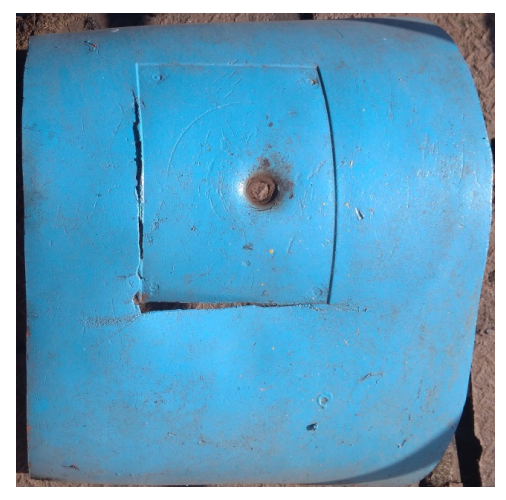

Gambar 2. Penutup Motor Listrik Fibre Cyclone dari Drum $P V C$ Bekas yang Dimodifikasi
Selain itu alat monitor keadaan temperatur motor masih manual menggunakan Termolaser gun. Hal tersebut dapat menjadi potensi penyebab motor listrik mengalami peningkatan temperatur berlebih (overheat) yang tidak dapat dikontrol dengan baik. Keadaan tersebut disebut sebagai motor listrik terbakar.

Untuk menanggulangi hal tersebut, melalui penelitian ini dirancang suatu sistem untuk memonitor secara realtime perubahan temperatur motor listrik 3 (tiga) fasa yang dilengkapi dengan indikator-indikator untuk sistem peringatan dini dan sistem trip otomatis manakala temperatur motor telah mencapai batas ambang atau overheated.

\section{Studi Literatur \\ 2.1 Motor Listrik 3 (Tiga) Fasa}

Konstruksi motor listrik 3 (tiga) fasa terdiri dari 2 bagian utama, yaitu stator dan rotor ${ }^{[1]}$. Stator dan rotor dipisahkan oleh celah udara yang jaraknya sangat kecil berkisar dari $0,4 \mathrm{~mm}$ sampai $4 \mathrm{~mm}^{[1,2]}$. Selain itu, konstruksi tambahan yang bukan bagian utama diatas antara lain rumah stator, tutup stator, kipas, dan terminal hubung ${ }^{[3]}$. Kumparan yang berada pada bagian stator (umumnya) maupun rotor memiliki batas kenaikan temperatur yang terbagi menjadi 4 (empat) kelas isolasi. Menurut NEMA, JIS C 4003, dan IEC Publication 85. Kelas isolasi menjadi tolak ukur usia pakai (life time) dari suatu motor listrik. Setiap kenaikan $10{ }^{\circ} \mathrm{C}$ akan menyebabkan life time motor listrik berkurang sebanyak $50 \%$ dari life time perancangan ${ }^{[4]}[5]$.

Tabel 2.1 Batas Kenaikan Temperatur

Kumparan Motor Listrik 3 (Tiga) Fasa [4]]

\begin{tabular}{|c|c|c|}
\hline No. & $\begin{array}{c}\text { Kelas } \\
\text { Isolasi }\end{array}$ & $\begin{array}{c}\text { Batas Maksimum } \\
\text { Temperatur Kumparan } \\
\left({ }^{\circ} \mathbf{C}\right)\end{array}$ \\
\hline 1. & A & 105 \\
\hline 2. & B & 130 \\
\hline 3. & F & 155 \\
\hline 4. & H & 180 \\
\hline
\end{tabular}

\subsection{Pengukuran dan Instrumentasi}

Pengukuran (measurement) adalah membandingkan suatu besaran yang tidak diketahui harganya atau nilainya dengan besaran yang telah diketahui nilainya ${ }^{[6]}$. Suatu sistem pengukuran atau proses pengukuran bertujuan 
Research Paper Vol 3, No 2, Tahun 2021

untuk menghubungkan antara proses (process) dengan pengamat (observer) melalui rangkaian input (true value), proses (measurement system), dan output (measured value), dimana pengamat akan melihat hasil pengukuran sebagaimana ditunjukkan pada Gambar 2.1 ${ }^{[6]}$.

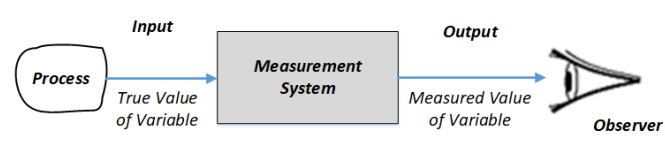

Gambar 2.1 Tujuan Sistem Pengukuran [6]

Sistem pengukuran dapat diterapkan untuk mengukur besaran temperatur. Pengukuran besaran temperatur menggunakan sensor temperatur dimana sensor yang mudah digunakan adalah sensor digital IC LM35. Pengukuran suhu menggunakan IC LM35 diintegrasikan dengan mikrokontroler sebagai unit pengolah sinyal dari sensor. Sensor ini dapat mengukur temperatur dari $-55^{\circ} \mathrm{C}$ sampai dengan $150{ }^{\circ} \mathrm{C}$ dengan relasi kenaikan $1^{\circ} \mathrm{C}$ sama dengan $10 \mathrm{mV}$. Dengan keakuratan sensor sebesar $0,5^{\circ} \mathrm{C}$ pada temperatur $25^{\circ} \mathrm{C}{ }^{[7]}$. Sinyal yang dikirim sensor IC LM35 berupa tegangan listrik DC (Direct Current) antara 0 (nol) volt sampai dengan 5 (lima) volt. Ketika temperatur bernilai $1{ }^{\circ} \mathrm{C}$ berarti tegangan listrik yang dikirim ke kontroler ( $V$ outsensor) adalah sebesar $0,001 \mathrm{~V}$ sesuai Persamaan 2.1 berikut ${ }^{[7]}$.

$\frac{\text { Voutsensor }}{10 \mathrm{mV}}=$ Temperatur $\left({ }^{\circ} \mathrm{C}\right)$

Sistem kontrol dilakukan terhadap hasil suatu pengukuran yang dibandingkan dan diperhitungkan, kemudian setelah didapatkan hasil perhitungan baik melalui alat atau manusia akan dilakukan tindakan perbaikan. Sistem kontrol terdiri dari 3 (tiga) bagian utama, yaitu

\subsection{Ergonomi}

Salah satu tinjauan yang perlu dipertimbangkan dalam merancang suatu sistem atau alat agar memenuhi bagian dari aspek ergonomi adalah tinjauan antropometri. Antopometri adalah pengukuran dimensi tubuh atau karakteristik fisik tubuh lainnya yang relevan dengan desain suatu barang yang dipakai ${ }^{[13]}$. Dengan tinjauan tersebut, penempatan perangkat memerlukan pertimbangan bahwa saat operator melakukan sensor, kontroler, dan aktuator. Sensor merupakan bagian yang berhubungan langsung dengan objek yang dapat merespon adanya perubahan lingkungan. Perubahan ini diterima oleh kontroler berupa sinyal listrik. Kontroler berfungsi sebagai otak yang dapat di-set up atau diprogram sedemikian rupa untuk memberikan perintah kepada aktuator. Aktuator dapat berupa tindakan mekanis (relay) ataupun display. Jenis sistem kontrol terbagi menjadi 2 (dua), yaitu sistem kontrol terbuka (open loop control system) dan sistem kontrol tertutup (close loop control system). Perbedaan mendasar dari kedua sistem tersebut adalah penggunaan umpan balik (feed back). Pada sistem kontrol tertutup (kontrol otomatis) menggunakan umpan balik, sedangkan pada sistem kontrol terbuka tidak menggunakan umpan balik ${ }^{[8]}$.

\subsection{Mikrokontroler}

Mikrokontroler adalah sebuah komputer kecil yang dikemas dalam bentuk chip IC (Integrated Circuit) dan dirancang untuk melakukan tugas atau operasi tertentu [9]. Arduino memiliki konfigurasi input atau output yang sederhana dan dapat dikembangkan melalui berbagai sumber kode program dan dihubungkan dengan berbagai perangkat keras seperti sensor digital atau analog, display, relay, atau lampu indikator ${ }^{[10]}$. Untuk memprogram board Arduino dibutuhkan aplikasi IDE (Integrated Development Environment) bawaan Arduino. Aplikasi ini berguna untuk membuat, membuka, dan mengedit sketch Arduino ${ }^{[1]}$. Sketch merupakan source code yang berisi logika dan algoritma yang akan diunggah (upload) ke dalam IC mikrokontroler ${ }^{[12]}$. Default Arduino IDE telah dilengkapi dengan library-library source code berbahasa $C$

pemantauan terhadap perangkat tersebut, tidak menimbulkan kelelahan akibat besar sudut pandang (dalam derajat) melebihi batas, yaitu > $30^{\circ}{ }^{[14]}$.

\section{Metode Perancangan}

Secara umum, sistem yang dirancang merupakan suatu alat untuk melakukan fungsi monitor dan kontrol yang menghubungkan motor listrik 3 (tiga) fasa dengan panel kontrol melalui sebuah 
Research Paper Vol 3, No 2, Tahun 2021

kontroler mikro (mikrokontroler) sebagaimana ditunjukkan pada Gambar 3.1.

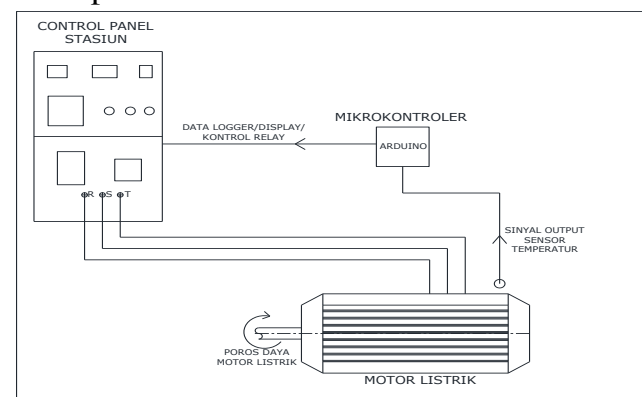

Gambar 3.1 Gambar Sistem Realtime Monitoring dan Trip Otomatis

Secara umum, sistem yang dirancang merupakan suatu alat baru untuk melakukan fungsi realtime monitoring temperatur dan kontrol (trip) otomatis terhadap motor listrik fibre cyclone melalui sebuah mikrokontroler yang ditempatkan pada panel kontrol stasiun nut dan kernel. Berbeda dengan TOR (Thermal Overload Relay) yang menjadikan besaran arus sebagai acuan untuk pemutus daya listrik (trip).

\subsection{Rancangan Rangkaian Elektronika Sistem}

Perancangan sistem dilakukan pada tingkat rekayasa elektronika yang fungsinya untuk memonitor temperatur terukur motor listrik 3 (tiga) fasa.

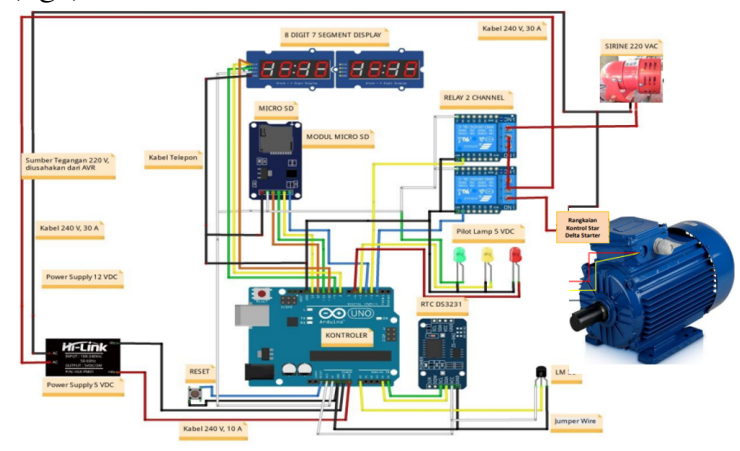

Gambar 3.2 Gambar Rangkaian elektronika sistem

Rancangan rangkaian sistem monitoring dirancang untuk menyimpan informasi temperatur dalam sebuah data loger, menampilkannya pada panel, memberikan indikasi berupa alarm jika temperatur berada pada set point tertentu dan melakukan trip manakala temperatur melampaui set point yang telah ditentukan. Gambar 3.2 menampilkan hubungan antara sensor sebagai pendeteksi temperatur (diletakkan dalam frame motor), mikrokontroler Arduino Uno sebagai kontroler, relay dan motor listrik 3 (tiga) fasa. Power supply yang digunakan bervariasi antara $5 V D C$ atau 12 VDC

\subsection{Pembuatan Sistem Realtime Monitoring dan Trip Otomatis Terhadap Motor Listrik 3 Fasa}

Dalam membuat rangkain kontrol terdapat 2 (dua) hal yang perlu diperhatikan agar fungsi trip otomatis dapat berjalan sebagaimana mestinya dan tidak mengganggu rangkaian Star Delta Starter Panel Kontrol Fibre Cyclone. Yang pertama adalah melakukan sambungan langsung (bypass) Push Button Start atau tombol berwarna hijau pada panel kontrol, kemudian yang kedua adalah memutus hubungan antara $M C B$ (Miniature Circuit Breaker) ke rangkaian Star Delta Starter. Rangkaian Star Delta Starter Motor Listrik Fibre Cyclone ditunjukkan pada Gambar 3.3 dibawah ini.

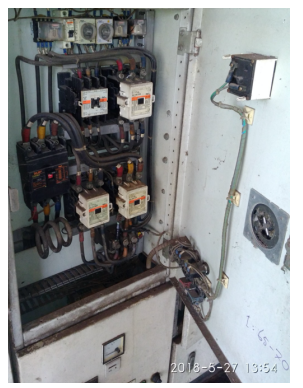

Gambar 3.3 Rangkaian Star Delta Starter Motor Listrik Fibre Cyclone

Panel kontrol Motor Listrik Fibre Cyclone dan panel kontrol tempat alat rancangan diletakkan terpisah sejauh \pm 4 (empat) meter. Sehingga dibutuhkan 2 (dua) potongan Kabel NYYHY $2 \times 0,75 \mathrm{~mm}^{2}$ dengan panjang 5 (lima) meter untuk menghubungkan 2 (dua) buah Switch Selector dengan rangkaian Star Delta Starter. Rangkaian antara Relay, Switch Selector, Baby Sirine, dan Star Delta Starter telah ditunjukkan pada Desain Rangakaian Kontrol sebagaimana bisa dilihat kembali pada Gambar 3.4. Pada kasus ini, Baby Sirine sebagai indikator suara diklasifikasikan ke dalam rangkaian kontrol karena fungsinya untuk menghidupkan dan mematikan Baby Sirine diperlukan Relay (Aktuator). 
Research Paper Vol 3, No 2, Tahun 2021

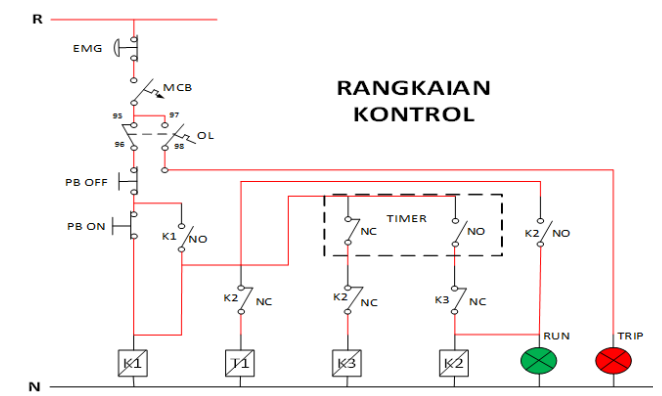

Gambar 3.4 Rangkaian Kontrol Star Delta Starter Motor Listrik Fibre Cyclone

\section{Hasil dan Diskusi}

Sistem trip otomatis merupakan salah satu teknik yang digunakan untuk mencegah motor listrik mengalami kelebihan panas (overheat). Pencegahan tersebut menggunakan prinsip sistem kontrol tertutup (close loop control system). Sensor IC LM35 mengirimkan sinyal ke Mikrokontroler, kemudian saat temperatur terukur (measured temperature) mencapai set point yang ditetapkan, maka kontroler akan menerima sinyal set point tersebut (feedback) dan meneruskan ke aktuator untuk memutuskan daya pada rangkaian kontrol star delta starter motor listrik.

Kelas isolasi yang digunakan pada kumparan motor listrik fibre cyclone adalah kelas $\mathrm{F}$. Informasi tersebut tertera pada spesifikasi motor listrik. Batas maksimum temperatur kumparan untuk kelas isolasi $\mathrm{F}$ adalah $155^{\circ} \mathrm{C}$. Alangkah baiknya jika kumparan dengan kelas isolasi $\mathrm{F}$ diberikan set point kelas isolasi A, yaitu sebesar $105^{\circ} \mathrm{C}$. Penggunan nilai batas sebesar $105^{\circ} \mathrm{C}$ merupakan salah satu upaya untuk menjaga usia pakai (life time) motor listrik agar mencapai batas waktu yang direncanakan bahkan melebihinya.

Batasan set point temperatur adalah $96^{\circ} \mathrm{C}$. Nilai tersebut merupakan nilai pengukuran temperatur pada bagian luar frame motor listrik sebagaimana titik pengambilan sampel yang dilakukan pada alat ukur Thermolaser. Penentuan set point $96^{\circ} \mathrm{C}$ karena memperhitungkan selisih temperatur antara alat yg dibuat dengan Thermolaser (alat ukur pembanding). Dari beberapa kali kalibrasi selisih antara Thermolaser (titik ukur di bagian luar frame) adalah $9^{\circ} \mathrm{C}$ lebih rendah dari IC LM35 yg dipasang di dalam frame elmo.

Jadi utuk display alat yang dirancang adalah 96 $\mathrm{C}$, namun sebenarnya di pembacaan Arduino adalah $105^{\circ} \mathrm{C}$ (kelas isolasi $\mathrm{A}$ )

Nilai sebenarnya dari sensor IC LM35 adalah $105^{\circ} \mathrm{C}$ seperti pada perhitungan:

Nilai Temperatur Sebenarnya $=96^{\circ} \mathrm{C}+9^{\circ} \mathrm{C}=$ $105^{\circ} \mathrm{C}$

Nilai pengukuran murni (nilai temperatur sebenarnya) dari sensor IC LM35 tetap menjadi acuan penentuan set point sebab posisi sensor adalah yang paling mendekati bagian stator motor listrik fibre cyclone. Oleh karena itu, set point yang digunakan pada kode program yang diunggah ke Mikrokontroler adalah nilai temperatur sesungguhnya dikurangi dengan angka 9 (sembilan)

Aktuator yang digunakan pada alat tersebut adalah Relay 2 (Dua) Channel yang dihubungkan ke rangkaian Star Delta Starter Motor Listrik Fibre Cyclone.

\subsection{Hasil Perancangan dan Pembuatan Sistem}

Sistem yang kemudian dapat disebut sebagai alat terbagi menjadi 5 (lima) bagian utama. Kelima bagian utama alat tersebut sebagaimana ditunjukkan pada Gambar 4.1 berikut :

1. Sensor; 2. Mikrokontroler, Display, Lampu Indikator; 3. Indikator Suara; 4. Switch Selector; dan 5. Power Supply. 


\section{Research Paper Vol 3, No 2, Tahun 2021}

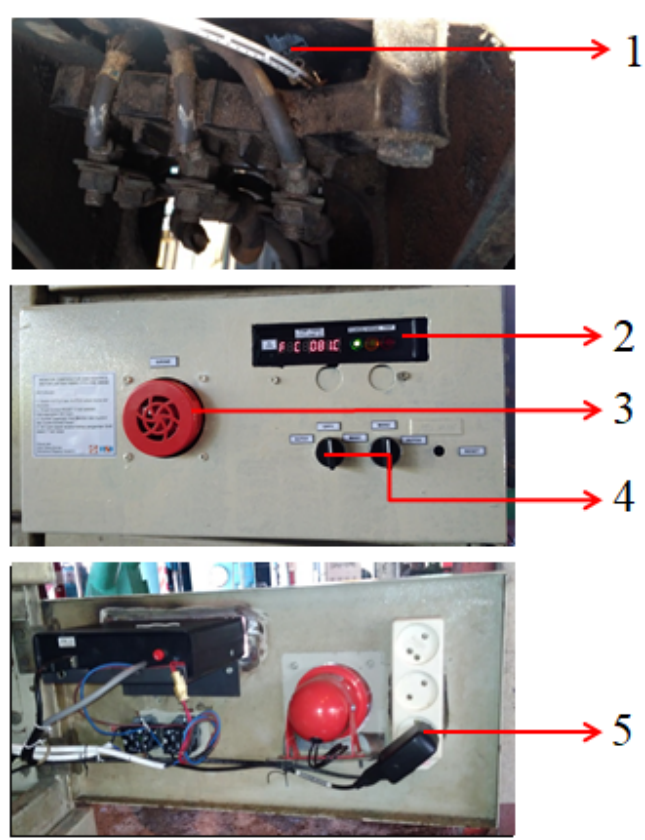

Gambar 4.1 Hasil Perancangan Alat

1. Sensor IC LM35 dirangkai dalam sebuah bentuk modul kompak berbahan $P C B$. Dalam pemasangan (instalasi) sensor ini, digunakan isolator dari Double Foam Tape untuk mencegah kabel sensor mengalami kerusakan akibat temperatur diatas $100{ }^{\circ} \mathrm{C}$. Modul tersebut diletakkan di Bagian Dalam Frame Motor Listrik Fibre Cyclone.

2. Sinyal listrik dari sensor diolah oleh mikrokontroler dan ditampilkan dalam sebuah display serta tersimpan pada MicroSD sebagai suatu cara untuk melakukan realtime monitoring perubahan temperatur motor listrik. Dalam perancangan alat digunakan kontroler Arduino Uno R3. Kemudian, digunakan sebuah modul penampil data perubahan temperatur berupa Sevent Segment.

3. Pembacaan data temperatur dilakukan setiap 2,5 detik dan tersimpan pada MicroSD. Data temperatur yang tersimpan memiliki nilai yang lebih detail, yaitu nilai temperatur mencapai 2 (dua) angka desimal dibelakang koma. Misalnya pada display ditampilkan nilai temperatur sebesar $78{ }^{\circ} \mathrm{C}$, pada waktu yang bersamaan di MicroSD akan tersimpan nilai temperatur sebesar $78,56{ }^{\circ} \mathrm{C}$. Nilai yang ditampilkan pada display dirancang dalam bilangan bulat dengan maksud untuk efisiensi dalam pembacaan hasil pengukuran. Sebagai early warning, dipasang lampu indikator yang terdiri dari 3 (tiga) warna berjenis $L E D$. Warna pertama (hijau) yang menunjukkan alat sedang berjalan dengan baik dan kondisi temperatur motor listrik masih aman (Temperatur $<94$ ${ }^{\circ} \mathrm{C}$ ). Warna kedua (kuning) sebagai tanda bahwa temperatur motor listrik mulai meningkat diatas batas aman $\left(94{ }^{\circ} \mathrm{C}<\right.$ Temperatur $<96{ }^{\circ} \mathrm{C}$ ). Ketika lampu kuning menyala secara bersamaan sirine akan berbunyi untuk memperingatkan operator bahwa perlu dilakukan suatu tindakan. Kemudian, warna lampu ketiga (merah) merupakan penanda bahwa motor listrik mengalami trip atau mati. Alat yang dirancang dilengkapi dengan sebuah indikator suara sebagai peringatan dini (early warning) disamping lampu indikator. Dalam perancangan yang dilakukan, suara yang dikeluarkan terdiri dari 3 tahap yaitu : 1) tahap pertama sirine akan berbunyi selama 0,5 detik, kemudian akan berhenti bersuara selama 0,5 detik; 2) tahap kedua, sirine akan berbunyi selama 0,8 detik dan berhenti berbunyi selama 0,8 detik; 3) tahap akhir adalah sirine akan berbunyi selama 1,1 detik dan mengakhiri indikator suara setelah durasi tersebut terpenuhi.

4. Penggunaan rangkaian kontrol dapat dipilih sesuai kebutuhan proses produksi PKS, yaitu mode trip manual dan mode trip otomatis.

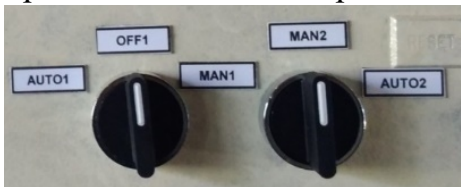

Gambar 4.2 Switch Selector untuk Menentukan Mode Sistem Kontrol

Petunjuk penggunaan sistem kontrol apakah secara otomatis atau secara manual sebagai berikut. 1) Sistem Kontrol Otomatis (Trip Otomatis) : Switch selector pertama (sebelah kiri) searah dengan pilihan AUTO1 dan switch selector kedua searah dengan pilihan AUTO2. 2) Sistem Kontrol Manual (Trip Manual) : Switch selector pertama searah dengan pilihan MAN1 dan switch selector kedua searah dengan pilihan MAN2. Sedangkan, pilihan OFF1 pada Switch Selector yang pertama adalah pilihan untuk menonaktifkan sistem kontrol dari aktuator.

5. Kebutuhan daya listrik yang digunakan pada alat realtime monitoring temperatur dan sistem trip otomatis adalah sebesar 45 Watt.

\subsection{Pengujian Sistem Monitor dan Kontrol}


Research Paper Vol 3, No 2, Tahun 2021

Hasil pengukuran alat hasil rancangan dibandingkan dengan alat ukur termolaser yang biasa digunakan oleh Departemen Workshop PKS Sungai Bengkal Jambi. Termolaser. Terdapat perbedaan hasil, sehingga dilakukan pengambilan sampel dari masing-masing alat ukur sebanyak 6 (enam) data perbandingan mulai tanggal 19 - 23 Mei 2018 yang menunjukkan nilai bervariasi dengan modus bernilai $9^{\circ} \mathrm{C}$ (sembilan) dan rata-ratanya sebesar $9^{\circ} \mathrm{C}$ (sembilan) sebagaimana ditampilkan pada Gambar 4.3. Variasi nilai temperatur tersebut diakibatkan perbedaan titik pengukuran temperatur antara Termolaser (luar frame) dengan sensor alat ini (dalam frame). Berdasarkan nilai modus dan rata-rata variasi selisih hasil ukur, pada tanggal 23 Mei 2018 dilakukan proses perubahan terhadap persamaan di dalam Sketch Arduino IDE seperti ditunjukkan pada Persamaan 4.1. Perubahan tersebut untuk mendapatkan data temperatur yang ditampilkan, disimpan, dan menjadi acuan sistem trip otomatis dapat diterima oleh pengguna alat yang dirancang. Berikut grafik hasil pengujian alat terhadap alat ukur yang biasa digunakan di PKS Sinarmas Group.

Perubahan persamaan tersebut yaitu hasil pengukuran dikurangi dengan angka $9^{\circ} \mathrm{C}$ (sembilan).

temp $=(($ mean $* 0,48)-9)\left[{ }^{\circ} \mathrm{C}\right]$

Simbol temp adalah asumsi untuk nilai temperatur yang ditampilkan, disimpan, dan dijadikan acuan sistem trip otomatis; mean adalah nilai rata-rata dari 500 kali pengambilan sampel yang dilakukan secara internal sistem pengukuran dalam waktu 2,5 detik; nilai 0,48 adalah nilai konversi $A D C$ (Analog to Digital Converter); dan angka 9 (sembilan) sebagai faktor penyesuaian nilai temperatur terhadap Termolaser.

\section{Grafik Variasi Selisih Hasil Ukur Antara Alat dan Termolaser $\left({ }^{\circ} \mathrm{C}\right)$}

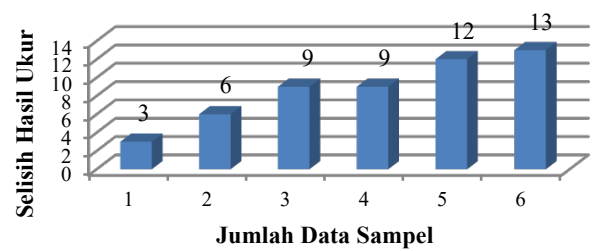

Gambar 4.3 Grafik Variasi Selisih Hasil Ukur antara Alat dan Termolaser $\left({ }^{\circ} \mathrm{C}\right)$

Perubahan dan pengujian pada tanggal 23 Mei 2018 pukul 15.54 WIB menunjukkan angka utama yang sama, yaitu sebesar $78{ }^{\circ} \mathrm{C}$. Pada Termolaser hasil pengukuran menunjukkan nilai pengukuran temperatur motor listrik Fibre Cyclone sebesar 78,0 ${ }^{\circ} \mathrm{C}$. Sedangkan, pada display alat yang dirancang menunjukkan nilai sebesar $78{ }^{\circ} \mathrm{C}$ dan pada Data Logger tersimpan nilai pengukuran sebesar $78,01^{\circ} \mathrm{C}$. Selisih nilai pengukuran alat dan termolaser adalah sebesar $0,01{ }^{\circ} \mathrm{C}$. Untuk memastikan hasil pengujian tersebut, dilakukan pengujian 2 (dua) kali lagi dengan hasil yang cukup baik yaitu selisih hasil pengukuran sebesar $0,00 \quad{ }^{\circ} \mathrm{C}$. Pada kasus ini, Termolaser diasumsikan sebagai alat ukur termometer konvensional yang biasa digunakan untuk mengukur temperatur mesin-mesin produksi di PKS Sungai Bengkal Jambi. Jika dijadikan sebagai acuan, maka perbedaan hasil pengukuran adalah sebesar $0,13 \%$ terhadap Termolaser.

Meskipun ketelitian tersebut tidak ditampilkan secara langsung pada seven segment display, melainkan dapat dilihat pada Data Logger yang telah tersimpan di Kartu Memori (MicroSD). Format file .CSV (Comma Separated Values)

\subsection{Ketelitian Alat Ukur}

Ketelitian alat ukur diuji dalam rentang waktu antara 23 Mei s.d. 12 Juni 2018 pada saat belum dilakukan proses produksi (motor listrik tidak beroperasi).

Tabel 4.1 Data Pengukuran Temperatur Motor Listrik

\begin{tabular}{|c|c|c|c|}
\multicolumn{4}{c|}{ Fibre Cyclone dari Data Logger } \\
\hline No. & $\begin{array}{c}\text { Tanggal } \\
\text { Data } \\
\text { Logger }\end{array}$ & $\begin{array}{c}\text { Waktu } \\
\text { (WIB) }\end{array}$ & $\begin{array}{c}\text { Rata-Rata } \\
\text { Temperatur } \\
\text { dari } 10 \\
\text { Pengambilan } \\
\text { Sampel }\left({ }^{\circ} \mathrm{C}\right)\end{array}$ \\
\hline 1 & 23 Mei & $\begin{array}{c}10: 25: 49 \text { s.d. } \\
10: 26: 35\end{array}$ & 25.36 \\
\hline 2 & 24 Mei & $\begin{array}{c}05: 52: 20 \text { s.d. } \\
05: 53: 06\end{array}$ & 25.29 \\
\hline 3 & 25 Mei & $\begin{array}{c}05: 45: 10 \text { s.d. } \\
05: 45: 56\end{array}$ & 25.45 \\
\hline 4 & 26 Mei & $\begin{array}{c}06: 55: 32 \text { s.d. } \\
06: 56: 18\end{array}$ & 25.36 \\
\hline 5 & 27 Mei & $\begin{array}{c}07: 26: 21 \text { s.d. } \\
07: 27: 07\end{array}$ & 25.72 \\
\hline 6 & 28 Mei & $\begin{array}{c}11: 19: 41 \text { s.d. } \\
11: 20: 26\end{array}$ & 25.47 \\
\hline 7 & 29 Mei & $\begin{array}{c}16: 29: 26 \text { s.d. } \\
16: 30: 11\end{array}$ & 25.44 \\
\hline
\end{tabular}


Research Paper Vol 3, No 2, Tahun 2021

\begin{tabular}{|c|c|c|c|}
\hline 8 & 30 Mei & $\begin{array}{c}\text { 09:04:51 s.d. } \\
\text { 09:05:36 } \\
\end{array}$ & 25.52 \\
\hline 9 & $31 \mathrm{Mei}$ & $\begin{array}{c}01: 47: 46 \text { s.d. } \\
01: 48: 31\end{array}$ & 25.82 \\
\hline 10 & $31 \mathrm{Mei}$ & $\begin{array}{c}02: 04: 31 \text { s.d. } \\
\text { 02:05:16 }\end{array}$ & 25.78 \\
\hline 11 & $31 \mathrm{Mei}$ & $\begin{array}{c}05: 35: 51 \text { s.d. } \\
05: 36: 36\end{array}$ & 25.25 \\
\hline 12 & 1 Juni & $\begin{array}{c}15: 38: 51 \text { s.d. } \\
15: 39: 36\end{array}$ & 25.66 \\
\hline 13 & 1 Juni & $\begin{array}{c}\text { 08:09:41 s.d. } \\
\text { 08:10:26 }\end{array}$ & 25.53 \\
\hline 14 & 2 Juni & $\begin{array}{c}04: 23: 16 \text { s.d. } \\
04: 24: 01\end{array}$ & 25.54 \\
\hline 15 & 3 Juni & $\begin{array}{c}15: 37: 26 \text { s.d. } \\
15: 38: 11\end{array}$ & 25.82 \\
\hline 16 & 3 Juni & $\begin{array}{c}15: 49: 36 \text { s.d. } \\
15: 50: 21\end{array}$ & 25.73 \\
\hline 17 & 4 Juni & $\begin{array}{c}\text { 13:49:01 s.d. } \\
\text { 13:49:46 }\end{array}$ & 25.11 \\
\hline 18 & 5 Juni & $\begin{array}{c}07: 19: 56 \text { s.d. } \\
07: 20: 41\end{array}$ & 25.19 \\
\hline 19 & 5 Juni & $\begin{array}{c}11: 47: 36 \text { s.d. } \\
11: 48: 21\end{array}$ & 25.59 \\
\hline 20 & 6 Juni & $\begin{array}{c}07: 24: 41 \text { s.d. } \\
07: 25: 26\end{array}$ & 25.36 \\
\hline 21 & 6 Juni & $\begin{array}{c}20: 18: 41 \text { s.d. } \\
20: 19: 26\end{array}$ & 25.81 \\
\hline 22 & 7 Juni & $\begin{array}{c}12: 43: 46 \text { s.d. } \\
12: 44: 31\end{array}$ & 25.54 \\
\hline 23 & 7 Juni & $\begin{array}{c}20: 58: 31 \text { s.d. } \\
\text { 20:59:16 }\end{array}$ & 25.54 \\
\hline 24 & 10 Juni & $\begin{array}{c}13: 47: 37 \text { s.d. } \\
13: 48: 23\end{array}$ & 25.46 \\
\hline 25 & 11 Juni & $\begin{array}{c}00: 33: 53 \text { s.d. } \\
00: 34: 39\end{array}$ & 25.26 \\
\hline 26 & 11 Juni & $\begin{array}{c}06: 19: 30 \text { s.d. } \\
06: 20: 16\end{array}$ & 25.45 \\
\hline 27 & 11 Juni & $\begin{array}{c}15: 53: 37 \text { s.d. } \\
15: 54: 23\end{array}$ & 25.80 \\
\hline 28 & 11 Juni & $\begin{array}{c}21: 42: 49 \text { s.d. } \\
\text { 21:43:34 }\end{array}$ & 25.64 \\
\hline 29 & 12 Juni & $\begin{array}{c}16: 15: 44 \text { s.d. } \\
16: 16: 30\end{array}$ & 25.32 \\
\hline 30 & 12 Juni & $\begin{array}{c}18: 26: 33 \text { s.d. } \\
18: 27: 19\end{array}$ & 25.66 \\
\hline
\end{tabular}

Dari data rata-rata tersebut, didapatkan nilai ratarata akhir sebesar $25,52{ }^{\circ} \mathrm{C}$; nilai standar deviasi sebesar 0,196 atau jika dibulatkan menjadi 0,2; dan rentang dari nilai tertinggi dan nilai terendah sebesar $0,71{ }^{\circ} \mathrm{C}$ sebagaimana ditunjukkan pada Tabel 4.2 dibawah ini.

Tabel 4.2 Nilai Rata-Rata, Standar Deviasi, dan Rentang

\begin{tabular}{|c|c|c|}
\hline Average & $\begin{array}{c}\text { Standar } \\
\text { Deviasi }\end{array}$ & Rentang \\
\hline
\end{tabular}

\begin{tabular}{|l|l|l|}
\hline 25.51487 & $\mathbf{0 . 1 9 6 8 2 5}$ & 0.711 \\
\hline
\end{tabular}

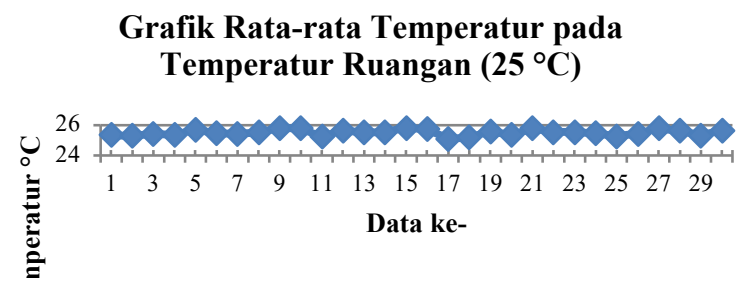

Gambar 4.4 Grafik Rata-Rata Temperatur pada Temperatur Ruangan

\subsection{Aspek Ergonomi}

Secara kuantitatif, dari jarak berdiri operator (90 $\mathrm{cm})$ dan selisih tinggi $(24 \mathrm{~cm})$ didapatkan besar sudut antara garis horizontal ke panel sebesar $14,9^{\circ}$ menggunakan persamaan Phytagoras dan Aturan Sinus.

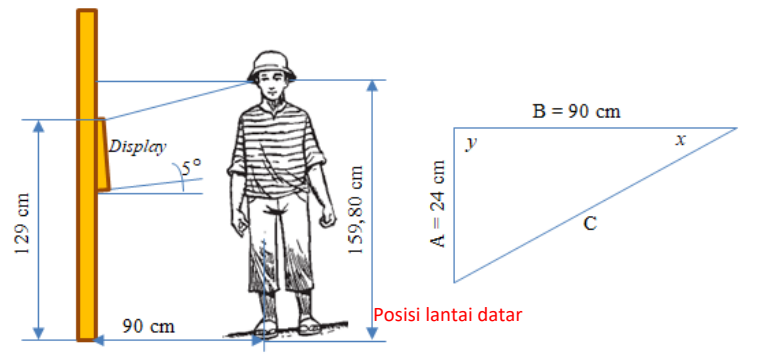

Gambar 4.5 Perhitungan Sudut Pandang Mata ke Alat

Kemudian, sebanyak 14 (93\%) dari 15 orang menyatakan bahwa alat yang dirancang inovatif, $11(73 \%)$ orang berpendapat mengenai alat yang dirancang bermanfaat dalam membantu kelancaran kegiatan pabrik. 11 orang juga menyatakan bahwa alat ini dapat membantu proses atau perawatan karena bersifat early warning. Kemudian, 9 (sembilan) orang menyatakan alat yang dirancang bagus secara keseluruhan yang dapat diartikan bahwa alat tidak hanya memenuhi aspek estetika ataupun sistem monitoring dan kontrol (trip otomatis), akan tetapi memenuhi aspek ergonomi. Menurut pandangan mereka, sebanyak 8 (delapan) orang menyatakan sistem pengukuran pada hasil rancangan alat adalah akurat. Selanjutnya, kurang dari 50\% mengatakan bahwa alat ini dapat diterapkan/dikembangkan pada motor listrik di stasiun lainnya dan 1 (satu) orang diantaranya tidak memberikan respon terhadap pertanyaan yang diajukan kepadanya. 
Research Paper Vol 3, No 2, Tahun 2021

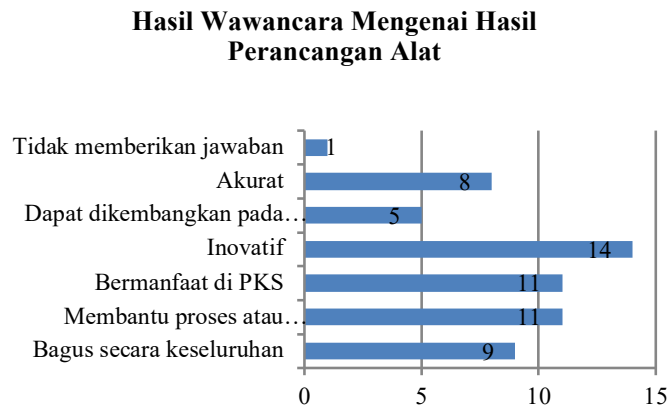

Gambar 4.6 Grafik Hasil Wawancara terhadap Alat yang Dirancang

Jumlah orang yang diwawancara minimal berjumlah 8 (delapan) sebagai orang-orang yang terlibat langsung dengan alat yang dirancang. Akan tetapi, berhasil dilakukan wawancara terhadap 15 orang yang berarti bahwa data kualitatif ini bisa dikatakan sebagai hasil sensus.

\subsection{Perbandingan Performansi Alat Ukur dengan Termolaser}

Termolaser merupakan alat ukur temperatur mesin-mesin produksi di PKS yang memiliki fungsi tunggal dan harga pembelian 1 (satu) unit adalah Rp. 1.200.000,-. Sedangkan, alat yang dirancang merupakan suatu sistem yang mampu mengintegrasikan antara sistem pengukuran, monitoring, dan kontrol otomatis serta aspek ergonomi dengan biaya pembuatan tidak lebih dari Rp. 500.000,-. Selain itu, alat yang dirancang memiliki ketelitian sampai dengan 2 (dua) angka desimal dibelakang koma, sedangkan termolaser mampu menampilkan hasil pengukuran sampai dengan 1 (satu) angka desimal dibelakang koma.

\section{Kesimpulan}

Berdasarkan hasil dan pembahasan pada bagian sebelumnya dapat dibuat kesimpulan yaitu sebagai berikut.

1. Upaya untuk melakukan pencegahan terjadinya overheat pada kumparan motor listrik 3 (tiga) fasa dapat dilakukan dengan membuat sistem yang telah diprogram agar dapat melakukan trip otomatis saat temperatur bagian dalam frame motor listrik sama dengan atau diatas set point, yaitu $>$
$105{ }^{\circ} \mathrm{C}$. Set point tersebut lebih rendah dibandingkan dengan batas maksimum temperatur operasi kumparan kelas isolasi $\mathrm{F}$ $\left(155^{\circ} \mathrm{C}\right)$.

2. Perancangan dan pembuatan sistem realtime monitoring temperatur dan trip otomatis berhasil dilakukan karena fungsi realtime monitoring temperatur dan trip otomatis (kontrol otomatis) berfungsi dengan baik; membutuhkan daya rendah sebesar 45 Watt; biaya pengadaan lebih murah daripada biaya pengadaan Termolaser SKF TMTL500 dengan selisih harga sebesar Rp. 700.000,-; memiliki fungsi untuk mengukur, memonitor secara realtime, menyimpan data pengukuran (data logger), kontrol otomatis sesuai program yang dibuat pada sistem; dan memiliki nilai ergonomi karena secara kuantitatif dan kualitatif telah memenuhi aspek ergonomi.

3. Performa alat ukur yang telah dirancang lebih teliti dibandingkan dengan Termolaser dan memiliki nilai kesalahan pengukuran dibawah $1 \%$ atau $1{ }^{\circ} \mathrm{C}$.

\section{Ucapan terima kasih}

Terima kasih kepada pihak Sungai Bengkal mill Jambi yang telah berkenan memberikan ruang untuk melaksanakan penelitian ini, serta Tim JVTI ITSB yang telah memberikan ruang untuk dapat diterbitkannya penelitian ini.

\section{Referensi}

[1] ----. ----. ----. Bab II Motor Induksi Tiga Fasa. Diakses dari http://repository. usu.ac.id/bitstream/handle/123456789/20 004/Chapter\%20II.pdf?sequence=3.

[2] Kuswoyo, Didit Very. (2016). Sistem Proteksi Motor Induksi 3 Fasa dari Gangguan Tidak Seimbang dan Temperatur Lebih Menggunakan Mikrokontroler. Skripsi, Fakultas Teknik, Universitas Lampung.

[3] Faurasyidi, Alkula. (2011). Modul Perbaikan Motor Listrik. Modul Perbaikan Motor Listrik Tingkat XI. SMK Muhammadiyah 1, Klaten Utara.

[4] ----. (2007). Insulation Class. Diakses dari http://tristate.apogee.net/mnd/mfnrins.asp 
Research Paper Vol 3, No 2, Tahun 2021

. Diakses pada 26 Mei 2018 pukul 12.33 WIB.

[5] ----. ---. ThreeBond Technical News. Three Bond CO., LTD. Jepang.

[6] Bentley, John P.. (2005). Principles of Measurement Systems, Fourt Edition. Pearson Prentice Hall. England.

[7] Syam, Rafiuddin. (2013). Dasar-Dasar Teknik Sensor untuk Beberapa Kasus Sederhana. Fakultas Teknik Universitas Hasanuddin. Makassar.

[8] Ogata, Katsuhiko. ----. Modern Control Engineering Fifth Edition. Prentice Hall. New Jersey.

[9] Pengertian Mikrokontroler (Microcontroller) dan Strukturnya. Diakses dari https://teknikelektronika.com/pengertianmikrokontroler-microcontroller-strukturmikrokontroler/. Diakses pada 19 Mei 2021 pukul 14:45 WIB
[10] Desai, Pratik. (2015). Python Programming for Arduino, Development Practical Internet of Things Prototypes and Applications with Arduino and Python. Packt Publishing. Mumbai.

[11] What is Arduino. Diakses dari https://www.arduino.cc/en/Guide/Introdu ction. Diakses pada 19 Mei 2021 pukul 14:57 WIB.

[12] Massimo Banzi. (2011). Getting Started with Arduino. $2^{\text {nd }}$ Edition. O'Reilly.

[13] Tarwaka, dkk. (2004). Ergonomi untuk Keselamatan, Kesehatan Kerja dan Produktivitas. Uniba Press. Surakarta.

[14] Adnyani, I. A. Sri. (2015). Layout Proyektor LCD Yang Ergonomi Pada Ruang Kuliah Jurusan Teknik Elektro Universitas Mataram. Dielektrika, ISSN 2086-9487. Vol. 2, No 1:1 - 5. 